\title{
Characteristics of pulmonary infection after mitral valve repair in patients with metabolic syndrome and its relationship with blood pressure, blood glucose and blood lipid
}

\author{
PENG XIAO ${ }^{1}$, WEI SONG ${ }^{2}$ and ZHE HAN $^{3}$ \\ ${ }^{1}$ Department of Thoracic Surgery, Luoyang Center Hospital Affiliated to Zhengzhou University, Luoyang, Henan 471009; \\ ${ }^{2}$ Department of Cardiac Surgery, The Second People's Hospital of Liaocheng, Linqing, Shandong 252600; \\ ${ }^{3}$ Department of Cardiac Surgery, Affiliated Hospital of Hebei University, Baoding, Hebei 071000, P.R. China
}

Received January 3, 2018; Accepted September 7, 2018

DOI: $10.3892 /$ etm.2018.6839

\begin{abstract}
Characteristics of pulmonary infection after mitral valve repair in patients with metabolic syndrome (MS) and its relationships with blood pressure, blood glucose and blood lipid were investigated. Clinical data of 126 patients were retrospectively analyzed, and patients were divided into infection group $(n=19)$ and non-infection group $(n=107)$. The differences of MS components in patients between the two groups were compared, and the distribution of pathogens and related factors of pulmonary infection were analyzed. The postoperative pulmonary infection rate was $15.08 \%(19 / 126)$; the body mass index (BMI), blood pressure, fasting blood glucose (FBG), triglyceride, total cholesterol, low-density lipoprotein cholesterol, the extubation time of trachea cannula, ventilator use time, rethoracotomy hemostasis rate, sternal dehiscence rate and incidence of low-cardiac-output syndrome were higher and high-density lipoprotein (HDL-C), left ventricular ejection fraction (LVEF) was lower in the infection group than that in the non-infection group $(\mathrm{p}<0.05)$. The rate of postoperative pulmonary infection in patients with MS was higher than in those without MS $(\mathrm{p}<0.05)$. Cardiac function, BMI, FBG, HDL-C, LVEF value, extubation time of trachea cannula, ventilator use time, sternal dehiscence, rethoracotomy hemostasis and low-cardiac-output syndrome were independent risk factors for pulmonary infection after mitral valve repair in patients with MS. In conclusion, pulmonary infection easily occurs in patients with MS after mitral valve repair. Taking intervention measures according to the characteristics of pulmonary infection pathogens and predisposing factors is expected to reduce the incidence of pulmonary infection.
\end{abstract}

Correspondence to: Dr Zhe Han, Department of Cardiac Surgery, Affiliated Hospital of Hebei University, 212 Yuhuadong Road, Baoding, Hebei 071000, P.R. China

E-mail: mha2jug@163.com

Key words: mitral valve replacement, pulmonary infection, metabolic syndrome, blood glucose, blood lipid

\section{Introduction}

Valvular heart disease is one of the most common types of heart disease in the clinic, of which mitral valve disease appears most frequently. Due to the long-term abnormality of blood flow, low body immunity and malnutrition easily occurs making corporeity of patients susceptible $(1,2)$. Heart valve replacement is the main surgical mode in the treatment of valvular heart disease at present with a significant effect, which saves lives and improves the quality of life $(2,3)$. However, valve replacement must be performed under specific hypothermic cardiopulmonary bypass conditions, which are severe and time-consuming, involving operations of invasive and allogeneic implantation; it severely impairs the patient's immune system, and incurs various infections after operation, of which pulmonary infection is particularly significant, thus aggravating cardiopulmonary circulating load, and leading to prolonged hospitalization, increased hospital costs, and even danger to the lives of patients, seriously affecting the patient's surgical outcome and prognosis (4).

Metabolic syndrome (MS) is a multiple metabolic disorder mainly involving obesity, hyperinsulinemia, hyperglycemia, dyslipidemia and hypertension, and it is a disease closely related to cardiovascular diseases. The risk of coronary heart disease in patients with MS is increased 3-fold, cardiovascular mortality increased 2-fold, and the risk of total mortality increased 1.5-fold (5). The characteristics of pulmonary infection after mitral valve repair in patients with MS are rarely reported.

The aim of the current study was to investigate the characteristics of pulmonary infection after mitral valve repair in patients with MS and its relationship with blood pressure, blood glucose, blood lipid and other factors, and to take targeted measures to provide reference for reducing the incidence of pulmonary infection.

\section{Materials and methods}

Clinical data. The complete clinical data of 126 patients undergoing mitral valve replacement from March 2013 to February 2015 in Luoyang Center Hospital Affiliated to Zhengzhou University (Luoyang, China) were retrospectively 
Table I. Clinical data of 126 patients undergoing mitral valve replacement.

\begin{tabular}{lrc}
\hline Item & Case (n) & Constituent ratio (\%) \\
\hline Type of heart disease & & \\
Rheumatic heart disease & 112 & 88.89 \\
Congenital heart disease & 9 & 7.14 \\
Valvular degeneration & 5 & 3.97 \\
Cardiac function (grade) & & \\
I & 5 & 3.97 \\
II & 25 & 19.84 \\
III & 83 & 65.87 \\
IV & 13 & 10.32 \\
\hline
\end{tabular}

analyzed, including 45 males and 81 females, with an average age of $(47.12 \pm 6.98)$ years. Valve replacement was performed among patients under intravenous combined anesthesia and hypothermic cardiopulmonary bypass. The clinical data of all the patients are shown in Table I. Diagnostic criteria for pulmonary infection (6) were in accordance with the standards formulated by the Centers for Disease Control and Prevention (Atlanta, GA, USA). The patients were divided into the infection group $(n=19)$ and non-infection group $(n=107)$ according to whether pulmonary infection occurred. The diagnosis of MS is based on the recommendations of the Diabetes Branch of Chinese Medical Association (Beijing, China) on MS (7).

The present study was approved by the Ethics Committee of the Affiliated Hospital of Hebei University (Baoding, China), and the Ethics Committee of Luoyang Center Hospital Affiliated to Zhengzhou University (Luoyang, China). Written informed consents were signed by the patients or guardians.

\section{Methods}

Measurement of physiological indexes. The clinical data of all the patients were recorded, including age, sex, type of heart disease and cardiac function classification. Patients were weighed at fasting and with unlined clothes, and the height was measured. Each index was measured two times and averaged. Body mass index $(\mathrm{BMI})=$ body weight $/$ height $^{2}$. Blood pressure of brachial artery in the right upper extremity was measured (using mercury sphygmomanometer) after patients rested quietly for $15 \mathrm{~min}$, and the average was taken from the values of three times of blood pressure.

Detection of serological indexes. Fasting anterior cubital vein blood $(5 \mathrm{ml})$ was extracted from patients the next day in the morning, followed by anticoagulation, centrifugation at $3,000 \mathrm{x} \mathrm{g}$ at $4^{\circ} \mathrm{C}$ for $15 \mathrm{~min}$ and refrigeration at $4^{\circ} \mathrm{C}$, in preparation for the testing. The fasting blood glucose (FBG), triglyceride (TG), total cholesterol (TC), high-density lipoprotein cholesterol (HDL-C) and low-density lipoprotein cholesterol (LDL-C) were detected by enzyme method. Blood ( $2 \mathrm{ml}$ ) was collected from patients under the strict aseptic operation, and sent to the clinical laboratory of the hospital, followed by culture and identification of bacteria by specialized staff.

Statistical analysis. Data were analyzed by Statistical Product and Service Solutions 18.0 software (SPSS, Inc., Chicago, IL,
USA). The measurement data conforming to normal distribution were expressed as (mean \pm SD), and statistically analyzed by t-test and chi-square test. Univariate and multivariate logistic regression analyses were used to analyze the risk factors and independent risk factors of pulmonary infection after mitral valve repair in patients with $\mathrm{MS}$. $\mathrm{P}<0.05$ was considered to indicate a statistically significant difference.

\section{Results}

Pulmonary infection and comparison of metabolic indexes in patients between the two groups. There were 19 cases with pulmonary infection, and the infection rate was $15.08 \%$ (19/126). The remaining 107 patients were in the non-infection group. The BMI, blood pressure, FBG, TG, TC, LDL-C in the infection group were higher than those in the non-infection group, and HDL-C was lower in the infection group than that in the non-infection group. The differences were statistically significant $(\mathrm{p}<0.05)$ (Table II).

Relationship between MS and pulmonary infection. Of the 126 patients studied, 24 were complicated with MS, 10 of whom had pulmonary infection, with an infection rate of $41.67 \%$. Of the 102 cases without MS, 9 cases had pulmonary infection, and the infection rate was $8.82 \%$. The difference was statistically significant $(\mathrm{p}<0.05)$ (Table III).

Characteristics of pathogenic bacteria in pulmonary infection. By analyzing the blood samples of 19 mitral valve replacement patients with pulmonary infection and positive bacteriology, it was found that each specimen was detected with a single strain. Among them, 14 strains were gram-negative bacteria, accounting for $73.68 \%$, including 9 strains of Acinetobacter baumannii (47.37\%), 4 strains of Pseudomonas aeruginosa (21.05\%), 3 strains of Klebsiella pneumoniae (15.79\%), 2 strains of Enterobacter cloacae (10.53\%) and 1 strain of Escherichia coli (5.26\%); there were 3 strains of gram-positive bacteria, including 2 strains of Staphylococcus aureus (10.53\%), 1 strain of Staphylococcus epidermidis (5.26\%) and 1 strain of fungus (5.26\%) (Fig. 1).

Analysis of pulmonary infection factors. Among patients between the non-infection group and the infection group, left ventricular ejection fraction (LVEF) $(56.23 \pm 13.10)$ vs. $(44.14 \pm 12.16 \%)$, extubation time of trachea cannula: $(23.98 \pm 6.37)$ vs. $(29.60 \pm 6.85) \mathrm{h}$, ventilator use time: $(11.21 \pm 4.35)$ vs. $(17.01 \pm 5.52) \mathrm{h}$, suggesting that the LVEF value was distinctly lower in patients of infection group than that of non-infection group, extubation time of trachea cannula in infection group was markedly longer than that in non-infection group, and the differences were statistically significant $(\mathrm{p}<0.05)$ (Table IV). Among patients between non-infection group and infection group: Sternal dehiscence rate: 5.61 vs. $21.05 \%$, rethoracotomy hemostasis rate: 1.87 vs. $10.53 \%$, incidence of low-cardiac-output syndrome: 2.80 vs. $10.53 \%$, indicating that the incidence rates of sternal dehiscence, rethoracotomy hemostasis and low-cardiacoutput syndrome were obviously higher in infection group than those in non-infection group, and the differences were statistically significant $(\mathrm{p}<0.05)$ (Table V). Univariate analysis 
Table II. Comparison of metabolic indexes in patients between the two groups.

\begin{tabular}{|c|c|c|c|c|}
\hline Index & Non-infection group $(n=107)$ & Infection group $(\mathrm{n}=19)$ & t-value & P-value \\
\hline Age (years) & $47.31 \pm 6.87$ & $47.02 \pm 7.14$ & 0.14 & 0.09 \\
\hline $\operatorname{BMI}\left(\mathrm{kg} / \mathrm{m}^{2}\right)$ & $22.12 \pm 2.98$ & $24.90 \pm 4.86$ & 4.16 & 0.01 \\
\hline Systolic pressure (mmHg) & $110.23 \pm 21.14$ & $119.47 \pm 12.63$ & 2.25 & 0.04 \\
\hline Diastolic pressure (mmHg) & $65.57 \pm 13.70$ & $75.58 \pm 11.27$ & 2.98 & 0.03 \\
\hline FBG (mmol/l) & $4.96 \pm 1.32$ & $6.19 \pm 2.36$ & 2.36 & 0.04 \\
\hline $\mathrm{TG}(\mathrm{mmol} / \mathrm{l})$ & $1.08 \pm 1.01$ & $1.86 \pm 1.34$ & 4.10 & 0.01 \\
\hline $\mathrm{TC}(\mathrm{mmol} / \mathrm{l})$ & $4.19 \pm 0.13$ & $5.24 \pm 0.70$ & 2.32 & 0.04 \\
\hline LDL-C (mmol/l) & $3.40 \pm 0.56$ & $3.93 \pm 1.42$ & 3.45 & 0.02 \\
\hline HDL-C (mmol/l) & $1.02 \pm 0.35$ & $1.35 \pm 0.41$ & 3.09 & 0.03 \\
\hline
\end{tabular}

BMI, body mass index; FBG, fasting blood glucose; TG, triglyceride; TC, total cholesterol; LDL-C, low-density lipoprotein cholesterol; HDL-C, high-density lipoprotein cholesterol.

Table III. Relationship between MS and pulmonary infection.

\begin{tabular}{lcccc}
\hline Group & $\begin{array}{c}\text { Pulmonary } \\
\text { infection (n) }\end{array}$ & $\begin{array}{c}\text { Constituent } \\
\text { ratio (\%) }\end{array}$ & $\chi^{2}$ & P-value \\
\hline MS (n=24) & 10 & 41.67 & 9.54 & $<0.001$ \\
Non-MS (n=102) & 9 & 8.82 & & \\
\hline
\end{tabular}

MS, metabolic syndrome.
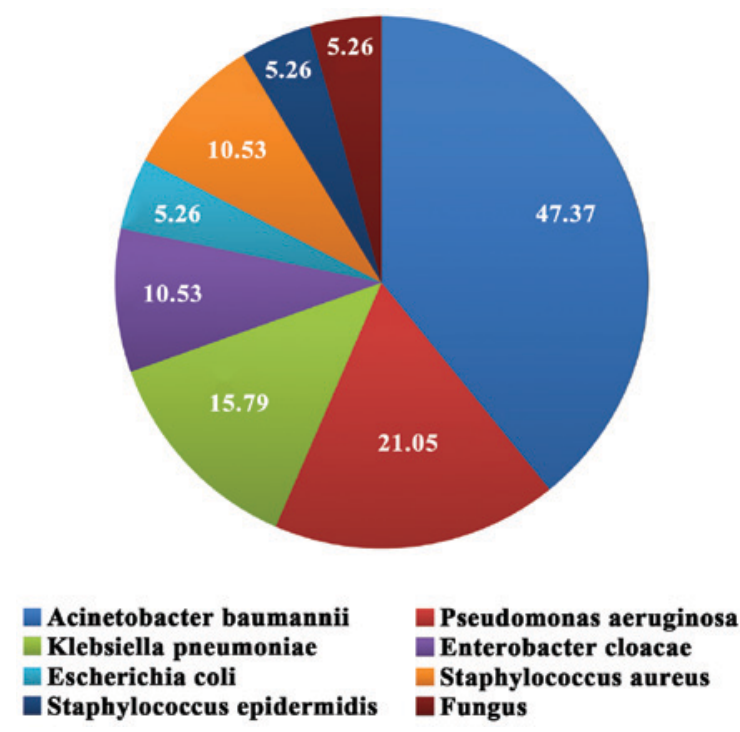

Figure 1. Constituent ratios of pulmonary infection pathogens (\%).

of risk factors for pulmonary infection was performed. The univariate analysis revealed that cardiac function, BMI, FBG, TG, LDL-C, HDL-C, LVEF value, extubation time of trachea cannula, ventilator use time, sternal dehiscence, rethoracotomy hemostasis and low-cardiac-output syndrome were risk factors for pulmonary infection after mitral valve repair in patients with MS (Table VI).

Multivariate analysis of independent risk factors for pulmonary infection. Multivariate logistic regression analysis on
Table IV. Analysis of pulmonary infection factors.

\begin{tabular}{lllll}
\hline & $\begin{array}{c}\text { Non-infection } \\
\text { group } \\
\text { Factor }\end{array}$ & $\begin{array}{c}\text { Infection } \\
\text { group } \\
(\mathrm{n}=107)\end{array}$ & t-value & P-value \\
\hline $\begin{array}{l}\text { LVEF (\%) } \\
\begin{array}{l}\text { Extubation } \\
\text { time of }\end{array}\end{array}$ & $56.23 \pm 13.10$ & $44.14 \pm 12.16$ & 6.45 & $<0.001$ \\
$\begin{array}{l}\text { trachea } \\
\text { cannula (h) }\end{array}$ & $23.98 \pm 6.37$ & $29.60 \pm 6.85$ & 8.17 & $<0.001$ \\
$\begin{array}{l}\text { Ventilator use } \\
\text { time (h) }\end{array}$ & $11.21 \pm 4.35$ & $17.01 \pm 5.52$ & 5.83 & $<0.001$ \\
& & & & \\
\hline
\end{tabular}

LVEF, left ventricular ejection fraction.

Table V. Analysis of pulmonary infection factors.

\begin{tabular}{|c|c|c|c|c|c|c|}
\hline \multirow[b]{2}{*}{ Factor } & \multicolumn{2}{|c|}{$\begin{array}{l}\text { Non-infection } \\
\text { group }(n=107)\end{array}$} & \multicolumn{2}{|c|}{$\begin{array}{c}\text { Infection } \\
\text { group }(n=19)\end{array}$} & \multirow[b]{2}{*}{$\chi^{2}$} & \multirow[b]{2}{*}{ P-value } \\
\hline & Case & $\begin{array}{l}\text { Incidence } \\
\text { rate }\end{array}$ & Case & $\begin{array}{l}\text { Incidence } \\
\text { rate }\end{array}$ & & \\
\hline $\begin{array}{l}\text { Sternal } \\
\text { dehiscence }\end{array}$ & 6 & 5.61 & 4 & 21.05 & 5.75 & 0.01 \\
\hline $\begin{array}{l}\text { Rethoracotomy } \\
\text { hemostasis }\end{array}$ & 2 & 1.87 & 2 & 10.53 & 6.53 & $<0.001$ \\
\hline $\begin{array}{l}\text { Low-cardiac-output } \\
\text { syndrome }\end{array}$ & 3 & 2.80 & 2 & 10.53 & 4.84 & 0.02 \\
\hline
\end{tabular}

the above risk factors revealed that 10 independent predictive risk factors for pulmonary infection were cardiac function, BMI, FBG, HDL-C, LVEF value, extubation time of trachea cannula, ventilator use time, sternal dehiscence, rethoracotomy hemostasis and low-cardiac-output syndrome (Table VII).

\section{Discussion}

According to literature, the prevalence of pulmonary infection after cardiac surgery is $2.80-15.30 \%$ (8), which is consistent 
Table VI. Univariate analysis of risk factors for pulmonary infection.

\begin{tabular}{lrr}
\hline Risk factor & OR $(95 \% \mathrm{CI})$ & P-value \\
\hline Age (years) & $1.104(1.007-1.068)$ & $>0.05$ \\
Type of heart disease & $1.001(0.958-0.997)$ & $>0.05$ \\
Cardiac function & $8.214(0.812-8.738)$ & $<0.05$ \\
BMI & $20.137(11.879-25.145)$ & $<0.05$ \\
Blood pressure & $0.962(0.661-1.374)$ & $>0.05$ \\
FBG & $20.121(11.476-26.769)$ & $<0.05$ \\
TG & $3.712(2.196-6.321)$ & $<0.05$ \\
TC & $1.121(0.715-1.474)$ & $>0.05$ \\
LDL-C & $12.741(6.243-25.681)$ & $<0.05$ \\
HDL-C & $9.514(5.576-15.901)$ & $<0.05$ \\
LVEF value & $14.016(6.438-24.013)$ & $<0.05$ \\
Extubation time of & $4.681(3.359-6.124)$ & $<0.05$ \\
trachea cannula & & \\
Ventilator use time & $10.827(7.109-16.032)$ & $<0.05$ \\
Sternal dehiscence & $28.142(12.365-33.248)$ & $<0.05$ \\
Rethoracotomy & $5.919(2.586-13.215)$ & $<0.05$ \\
hemostasis & & $<0.05$ \\
Low-cardiac-output & $4.231(2.057-8.243)$ & \\
syndrome & & \\
\hline
\end{tabular}

OR, odds ratio; CI, confidence interval; BMI, body mass index; FBG, fasting blood glucose; TG, triglyceride; TC, total cholesterol; LDL-C, low-density lipoprotein cholesterol; HDL-C, high-density lipoprotein cholesterol; LVEF, left ventricular ejection fraction.

Table VII. Multivariate analysis of independent risk factors for pulmonary infection.

\begin{tabular}{lrr}
\hline Risk factor & OR $(95 \%$ CI $)$ & P-value \\
\hline Cardiac function & $10.8(4.9-13.6)$ & $<0.05$ \\
BMI & $3.9(1.2-9.1)$ & $<0.05$ \\
FBG & $11.4(6.1-16.3)$ & $<0.05$ \\
HDL-C & $4.6(1.5-6.4)$ & $<0.05$ \\
LVEF & $25.1(12.7-38.3)$ & $<0.05$ \\
Extubation time of & $9.2(4.2-14.1)$ & $<0.05$ \\
trachea cannula & & \\
Ventilator use time & $21.6(10.2-28.2)$ & $<0.05$ \\
Sternal dehiscence & $15.3(7.2-20.4)$ & $<0.05$ \\
Rethoracotomy & $19.2(9.7-24.5)$ & $<0.05$ \\
hemostasis & & \\
Low-cardiac-output & $12.9(6.1-15.9)$ & $<0.05$ \\
syndrome & & \\
\hline
\end{tabular}

OR, odds ratio; CI, confidence interval; BMI, body mass index; FBG, fasting blood glucose; HDL-C, high-density lipoprotein cholesterol; LVEF, left ventricular ejection fraction.

with that of pulmonary infection after mitral valve replacement reported in this study (15.08\%). Moreover, the incidence of pulmonary infection in patients with MS is higher than that in patients without MS $(\mathrm{p}<0.05)$. MS is a morbid state with multiple metabolic disorders mainly involving obesity, hyperinsulinemia, hyperglycemia, dyslipidemia and hypertension, and it is closely related to cardiovascular disease (9).
Multivariate logistic regression analysis in this study revealed that BMI, FBG and HDL-C are independent risk factors for pulmonary infection after mitral valve repair in patients with MS. The study indicated that obesity increases the alveolar arterial oxygen difference in thoracic surgery, which leads to imbalance of ventilation and blood flow, easily resulting in hyoxemia (10). In addition, given that it causes difficulty in anesthesia intubation and large dosage of anesthetic drug and easily complicated reflux esophagitis, it is regarded as a risk factor of postoperative aspiration pulmonary infection. This study demonstrated that BMI in the group of pulmonary infection after mitral valve replacement was significantly higher than that in the group without pulmonary infection $(\mathrm{p}<0.05)$. Another important risk factor for postoperative infection of heart is diabetes mellitus $(11,12)$. If the patient has diabetes or liver disease before operation, it is more likely to have limited glucose utilization in the body and aggravate blood glucose; furthermore, the increase of blood glucose also increases the incidence of postoperative infection (13). This study showed that FBG in the group of pulmonary infection after mitral valve replacement was significantly higher than that in the group without pulmonary infection $(\mathrm{p}<0.05)$. In plasma, the binding of HDL-C with endotoxin has anti-endotoxemia effect (14). This study also found that HDL-C in the group with pulmonary infection after mitral valve replacement was lower than that in the group without pulmonary infection $(\mathrm{p}<0.05)$. Thus, with the decrease of HDL-C, the anti-endotoxemia effect is weakened, and the infection easily occurs. This study indicated that pulmonary infection easily occurs in patients with MS after mitral valve replacement, so attention should be paid to the risk of MS in clinical practice, and emphasize the early prevention and treatment of MS.

With the development of modern medicine, the curative effect of mitral valve replacement is beyond doubt. However, the incidence of postoperative pulmonary infection is still as high as $15.08 \%$ (19/126). Due to the different regions, times and ages, and with the advent of new antibacterial drugs, a large number of antibiotics are clinically abused, resulting in the constant change in the species of pathogenic bacteria, which brings difficulties to diagnosis and treatment. The majority of pathogenic bacteria causing pulmonary infection are gram-negative bacteria (73.68\%) (14/19), the top three are 9 strains of Acinetobacter baumannii (47.37\%), 4 strains of Pseudomonas aeruginosa (21.05\%) and 3 strains of Klebsiella pneumoniae (15.79\%). This study showed that the extubation time of trachea cannula, ventilator use time, rethoracotomy hemostasis rate, sternal dehiscence rate and incidence of low-cardiac-output syndrome in patients of pulmonary infection group were significantly higher than those of non-infection group, but LVEF value was lower in the infection group than that in the non-infection group, and the differences were statistically significant $(p<0.05)$. Multivariate logistic regression analysis in this study revealed that cardiac function, LVEF value, extubation time of trachea cannula, ventilator use time, sternal dehiscence, rethoracotomy hemostasis and low-cardiac-output syndrome were independent risk factors for pulmonary infection after mitral valve repair in patients with MS. Rethoracotomy hemostasis mostly belongs to emergency surgery, of which the disinfection effect is poorer and incomplete, which will cause more massive intrathoracic 
bleeding and larger trauma, further reducing the immune function of patients. In addition, allogeneic blood transfusion is needed for severely ill patients, which increases the risk of infection $(15,16)$. On the one hand, sternal dehiscence destroys the integrity of bony thorax; on the other hand, it increases the pain time of patients, seriously affects the cough and breathing of patients, causes weak cough and shallow and rapid breathing, and hinders secretion discharge from the respiratory tract (17). LVEF is an important index to evaluate cardiac function, and cardiac function reduces with the decrease of LVEF value (18). Once the left ventricular function is abnormal, pulmonary edema or congestion can be induced, affecting cardiac and pulmonary function. Therefore, the effective management of LVEF before surgery will contribute to the prognosis and rehabilitation of patients. Ventilator is necessary for assisted breathing of patients after heart valve replacement; the ventilator-associated complications, including respiratory tract infection and pulmonary infection, can occur if the ventilator is used improperly or over time (19). On the one hand, the airway, which is open to the outside world, loses its function of defense barrier; on the other hand, the connecting pipes of ventilator are easily polluted, and the purification degree of aspiration gas is low, leading to the invasion and colonization of pathogenic bacteria into lung incurring infection (20). The airway mucosa of patients with long-term intubation is easily damaged, plus the increase of secretions caused by foreign body stimulation, can induce infection (21). During the operation, the use of acid suppression agents reduces the secretion of gastric acid, and the intestinal flora moves into the respiratory tract, which will cause gram-negative bacilli to induce endogenous infection (22). After oral and tracheal intubation, the oral self purification capacity under the semi-open state decreases, leading to the excessive increase in oropharyngeal bacteria, and it will enter the lower respiratory tract with the invasive operation, thus incurring pulmonary infection (23). In order to obtain better surgical effect, shorten the operation and hospitalization time (24-26), we should pay attention to preoperative health education: i) To guide the cough method and expectoration manipulation before operation is conducive to the adequate and effective expectoration of patients after operation; ii) to guide the standard use of ventilator is helpful to prevent the occurrence of pulmonary infection; iii) to emphasize the oral cleaning care, strengthen the basic nutritional support and improve the patient's own state, are beneficial to ameliorate the treatment and prognosis, thus promoting the harmonious development of doctor-patient relationship.

\section{Acknowledgements}

Not applicable.

\section{Funding}

No funding was received.

\section{Availability of data and materials}

The datasets analyzed during the present study are not publicly available due to the protection of patient privacy but are available from the corresponding author on reasonable request.

\section{Authors' contributions}

PX and WS collected the patient clinical information and analyzed the data. PX wrote the manuscript and $\mathrm{ZH}$ helped with detection of serological indexes. All authors read and approved the final study.

\section{Ethics approval and consent to participate}

The present study was approved by the Ethics Committee of the Affiliated Hospital of Hebei University (Baoding, China), and the Ethics Committee of Luoyang Center Hospital Affiliated to Zhengzhou University (Luoyang, China). All the patients provided written informed consent for publication.

\section{Patient consent for publication}

Not applicable.

\section{Competing of interests}

The authors declare that they have no competing interests.

\section{References}

1. Blasi A, Muñoz G, de Soto I, Mellado R, Taura P, Rios J, Balust J and Beltran J: Reliability of thromboelastometry for detecting the safe coagulation threshold in patients taking acenocoumarol after elective heart valve replacement. Thromb Res 136: 669-672, 2015.

2. Weber B and Hoerstrup SP: The future of heart valve replacement. Eur Heart J 36: 326-328, 2015.

3. Zhang XW, Song ZG, Wang L, Lu FL, Zou LJ, Xu JB and Xu ZY: The use of intra-aortic balloon pump in patients undergoing heart valve replacement: Outcome and risk analysis. J Heart Valve Dis 23: 458-462, 2014.

4. Weimar T, Roser D, Liebrich M, Horke A, Doll N and Hemmer WB: Strategies for biological heart valve replacement: Stentless xenografts fail to evolve into an alternative pulmonary valve substitute in a Ross procedure. Biotechnol J 8: 345-351, 2013.

5. Eckle RH, Grundy SM and Zimmet PZ: The metabolism syndrome. Lancet 365: 1415-1428, 2005.

6. Li DL, Dong PS, Du LJ, Li ZZ, Sh XY and Fan XM: Analysis of related risk factors of pulmonary infection after heart valve replacement. J Hosp Infect 23: 3908-3910, 2013.

7. Metabolic syndrome study group of Chinese Diabetes Association. Recommendations of the Chinese Medical Association Diabetes Branch on metabolic syndrome. Chin J Diabetes Mellitus 12: 156-161, 2004 (In Chinese).

8. Riera M, Ibáñez J, Herrero J, Ignacio Sáez De Ibarra J, Enríquez F, Campillo $\mathrm{C}$ and Bonnín O: Respiratory tract infections after cardiac surgery: Impact on hospital morbidity and mortality. J Cardiovase Surg (Torino) 51: 907-914, 2010.

9. Salazar MR, Carbajal HA, Espeche WG, Dulbecco CA, Aizpurúa M, Marillet AG, Echeverría RF and Reaven GM: Relationships among insulin resistance, obesity, diagnosis of the metabolic syndrome and cardio-metabolic risk. Diab Vasc Dis Res 8: 109-116, 2011.

10. Suemitsu R, Sakoguchi T, Morikawa K, Yamaguchi M, Tanaka H and Takeo S: Effect of body mass index on perioperative complications in thoracic surgery. Asian Cardiovasc Thorac Ann 16: 463-467, 2008.

11. Lola I, Levidiotou S, Petrou A, Arnaoutoglou H, Apostolakis E and Papadopoulos GS: Are there independent predisposing factors for postoperative infections following open heart surgery? J Cardiothorac Surg 6: 151, 2011.

12. Sato H, Carvalho G, Sato T, Lattermann R, Matsukawa $T$ and Schricker T: The association of preoperative glycemic control, intraoperative insulin sensitivity, and outcomes after cardiac surgery. J Clin Endocrinol Metab 95: 4338-4344, 2010. 
13. Hu QG and Zheng QC: The influence of enteral nutrition in postoperative patients with poor liver function. World J Gastroenterol 9: 843-846, 2003.

14. Murphy AJ, Chin-Dusting JP, Sviridov D and Woollard KJ: The anti inflammatory effects of high density lipoproteins. Curr Med Chem 16: 667-675, 2009.

15. Habal P, Simek J and Stětina M: Improving of treatment safety in emergency thoracic surgery. Rozhl Chir 89: 261-264, 2010 (In Czech).

16. Zhang C, Gao J and He B: Analysis of related factors of patientos undergoing cardiac valve replacement complicated with pulmonary infection and nursing strategies of it. Chin Nurs Res 90: 64-66, 2008.

17. Weimar T, Roser D, Liebrich M, Horke A, Doll N and Hemmer WB: Strategies for biological heart valve replacement: Stentless xenografts fail to evolve into an alternative pulmonary valve substitute in a Ross procedure. Biotechnol J 8: 345-351, 2013.

18. Bax JJ, Visser FC, Poldermans D, Elhendy A, Cornel JH, Boersma E, Valkema R, Van Lingen A, Fioretti PM and Visser CA: Relationship between preoperative viability and postoperative improvement in LVEF and heart failure symptoms. J Nucl Med 42: 79-86, 2001.

19. Yang TH, Webb JG, Blanke P, Dvir D, Hansson NC, Nørgaard BL, Thompson CR, Thomas M, Wendler O, Vahanian A, et al: Incidence and severity of paravalvular aortic regurgitation with multidetector computed tomography nominal area oversizing or undersizing after transcatheter heart valve replacement with the Sapien 3: A comparison with the Sapien XT. JACC Cardiovasc Interv 8: 462-471, 2015

20. Phan K, Tsai YC, Niranjan N, Bouchard D, Carrel TP, Dapunt OE, Eichstaedt HC, Fischlein T, Gersak B, Glauber M, et al: Sutureless aortic valve replacement: A systematic review and meta-analysis. Ann Cardiothorac Surg 4: 100-111, 2015.
21. Cai XH: Risk factors for nosocomial pulmonary infection after tracheal intubation under general anesthesia. Chin J Nosocomiology 9: 1780-1782, 2011 (In Chinese).

22. Flynn DM, Weinstein RA and Kabins SA: Infections with gram-negative bacilli in a cardiac surgery intensive care unit: the relative role of enterobacter. J Hosp Infect 11 (Suppl A): 367-373, 1988.

23. Farran L, Llop J, Sans M, Kreisler E, Miró M, Galan M and Rafecas A: Efficacy of enteral decontamination in the prevention of anastomotic dehiscence and pulmonary infection in esophagogastric surgery. Dis Esophagus 21: 159-164, 2008.

24. Miljeteig I, Skrede S, Langørgen J, Haaverstad R, Jøsendal O, Sjursen $\mathrm{H}$ and Norheim OF: Should patients who use illicit drugs be offered a second heart-valve replacement? Tidsskr Nor Laegeforen 133: 977-980, 2013 (In Norwegian).

25. Berg SK, Zwisler AD, Pedersen BD, Haase K and Sibilitz KL: Patient experiences of recovery after heart valve replacement: Suffering weakness, struggling to resume normality. BMC Nurs 12: 23, 2013.

26. Nietlispach F and Maisano F: Balloon post-dilation after transcatheter aortic valve replacement: A solution worth trying in patients with residual aortic insufficiency. JACC Cardiovasc Interv 7: 790-791, 2014.

This work is licensed under a Creative Commons Attribution-NonCommercial-NoDerivatives 4.0 International (CC BY-NC-ND 4.0) License. 